\title{
Achieving the Potential of Health Information Technology
}

\author{
Helen R. Burstin, MD, MPH \\ National Quality Forum, Washington, DC, USA.
}

$\mathrm{J}$ Gen Intern Med 23(4):502-4

DOI: $10.1007 / \mathrm{s} 11606-008-0552-\mathrm{x}$

(c) Society of General Internal Medicine 2008

A ccording to the dictionary, "potential" means "existing in possibility." ${ }^{1}$ For many of us who desperately want health information technology (IT) to be the long, sought after panacea that will lead to dramatic improvements in quality and safety, there is a strong desire to get to "existing in reality." A growing sense of awareness and urgency around the current state of health care quality in America continues to push us toward action and health IT. The ability to standardize highrisk processes, such as drug prescribing, and remind providers to order evidence-based preventive services seems so logically connected to better care. There is also a growing sense of impatience among the public with low uptake.

Significant barriers remain in our path toward greater adoption of health IT. The most frequently cited barrier remains the upfront cost and maintenance of these electronic systems. An emerging linkage between payment and quality may help if electronic health records allow us to more easily report on quality measures and get paid for higher performance. Another barrier that does not get as much attention is the perceived lack of evidence among providers that electronic health record systems can improve quality and safety while maintaining or improving clinician workflow and efficiency. The strong desire to believe that health IT systems will work as expected has often overshadowed the reality that an IT system cannot be the sole quality improvement intervention. As the Veterans Health Administration experience in diabetes has demonstrated, a computer system can only move us so far unless we invest in a broader process redesign and improvement efforts. ${ }^{2}$

This special issue of the Journal of General Internal Medicine is especially exciting because it shows the real potential of health IT-warts and all-in real-world settings. These articles help us better understand what is needed to drive toward broader implementation and avoid the missteps that continue to limit the broader adoption of health IT. Among the various forms of health IT, there is often the greatest enthusiasm for the perceived simplicity and great potential of electronic prescribing. The American Health Information Community recently recommended that Secretary Leavitt push on the legislation that would mandate the use of electronic prescribing. The articles by Crosson et al. ${ }^{3}$ and Fischer et al. ${ }^{4}$ may temper our expectations that a legislative mandate will be enough to move us toward more universal adoption. Among other factors, the physicians who had the most realistic expectations had better uptake of electronic prescribing. We clearly need to avoid "overselling" the potential of these systems to make care safer and more efficient until we get a better understanding of the barriers toward routine use.

Although there is a growing evidence base for the efficacy of clinical decision support systems and reminders to improve the quality of certain aspects of clinical care, ${ }^{5}$ evidence of effectiveness is still lacking. Again, the use of reminders and decision support seems so obvious. We have a remarkably slow rate of diffusion of medical knowledge in the United States, and reminding busy clinicians to do what is evidence based seems so intuitive. For example, the 1977 landmark study on the use of pneumococcal vaccine has only translated into $57 \%$ of eligible patients receiving the vaccine. ${ }^{6}$ However, the articles in this special issue should give us pause about the translation of these systems to improved effectiveness in real-world settings. The article by Fung et al. makes a strong case for the need for end-user input into the development of reminder systems that can better fit into the clinical workflow. ${ }^{7}$ The important new work by Hicks et al. and Weber et al. in this journal offer evidence that clinical decision support can help to improve the management for common chronic illnesses, such as hypertension and diabetes. ${ }^{8,9}$ However, the actual degree of improvement demonstrated in the outcomes for these chronic illnesses should give us pause. The complementary approach of providing electronic information and decision support directly to patients will hopefully increase patient engagement as well as improve outcomes. The article by Hess et al. in this issue reminds us that although most patients could complete an electronic screening questionnaire, ${ }^{10}$ the digital divide is still with us for some of our most vulnerable patients in need of the greatest improvement.

Whereas electronic health records and decision support systems have primarily focused on improved effectiveness and patient safety, health information exchange has the potential to improve the efficiency of care. We have all ordered a test because we needed the result although we knew that it had been done by another doctor or another hospital in the recent past. This reality points out another limitation to the uptake of electronic health records by physicians - we often don't have the critical information we need from consultants, laboratories, or hospitals. The President's Information Technology Advisory Council (PITAC) estimated that every seventh admission may be unnecessary and every fifth lab test may be unnecessary. ${ }^{11}$ Whereas regional health information exchange offers great promise to reduce these unnecessary redundancies in our health care system, there is little evidence to back up this assertion. In this issue, Kern et al find that access to electronic results via an internet portal can significantly improve the quality of care. ${ }^{12}$ Although there are questions regarding the business case for these emerging regional health 
information exchanges, the potential to provide bridges to the data we need-laboratories, radiology reports, left ventricular systolic function tests, consult notes, medication lists, and discharge summaries-could prove to be the critical lynchpin in our ability to care for patients across transitions and episodes of care. The inclusion of key public health data, such as immunizations, could further help to strengthen the clinical-public health interface and move us toward a renewed focus on population health.

The need to improve patient safety has clearly placed the highest expectations on health IT systems such as computerized provider order entry (CPOE). Some of these expectations appear supported by the literature that includes examples of remarkable reductions in medication errors associated with CPOE systems. ${ }^{13}$ However, the proof that these systems perform in less IT-savvy institutions remains elusive. ${ }^{14} \mathrm{We}$ need to continue to learn about what happens when these systems are adopted in a full range of settings. The systematic review by Wolfstadt et al. offers up some mixed results on the effectiveness of CPOE systems. ${ }^{15}$ On the positive side, the articles by Dollarhide et al. and Foster et al. offer important insights on how to weave patient safety reporting into the flow of patient care. ${ }^{16,17}$ The article by Dollarhide et al. suggests that the use of a handheld software application increased the number of confidential reports for medication events, especially among nurses. Similarly, Foster et al. incorporated electronic reporting of safety events into the electronic resident sign-out system. Both of these interventions suggest that moving safety reporting into the flow of patient care can make it easier to gather the data we need to drive improvement. As Mark Chassin said more than a decade ago- -we need to make the right thing the easy thing to do." If providers need to expend extraordinary effort outside of routine care to report on patient safety events, we will continue to be hamstrung by our inability to examine what goes wrong and fix it.

Transparency in performance measurement is an important cultural change in the health care landscape that may serve as an additional driver toward greater use of health IT in practice. The call for transparency will necessitate greater availability of quality measures for public reporting. Although not specifically addressed in this issue, the rich clinical environment of an electronic health record should allow us to produce betterquality measures. This will hopefully increase physician acceptance of quality measurement and allow us to routinely assess how close we are to achieving evidence-based care for our patients. The measures produced by electronic health record systems should also be a critically important driver of quality improvement as we can only improve what we can measure. Much work needs to be done before most electronic health records can routinely produce quality measures, but it is clearly the direction for the future. In addition, while we are working on quality measurement, we can take the opportunity to link the clinical information in electronic health records to the demographic data in our practice management systems so that we can routinely measure disparities in all we do.

Finally, I would like to end on a positive and pragmatic note-what we can do as general internists to move this potential to reality. First, general internists need to weigh in on the specific applications of health IT that we think will make the most difference in the quality and safety for our patients. As demonstrated in this special issue, our research-minded colleagues are making important progress in teaching us should we should do-such as speaking to end-users-and what not to do-such as setting unreasonable expectations. Our clinician-educator colleagues can help by serving as the beta testers for adoption of these electronic systems so they can be improved and fit better into the flow of care. Whereas many practices cannot adopt the full array of electronic health record systems, we can begin to incrementally adopt the electronic systems that show the most promise. For some generalists who admit many patients, the connectivity to the local hospital may be most important to ensure effective care transitions. Generalists often know best what our patients need, and we can advocate for the critical pieces of electronic data that we know we will need, such as discharge summaries and the medication reconciliation listing from the hospital sent to us electronically before the patient leaves the hospital. As the dominant clinical educators in our departments, we can incorporate the importance of health IT and interconnectivity into our teaching plans. The vision of an advanced medical home for primary care clearly includes the ability to effectively utilize the health IT systems that can help to improve the quality and safety of health care.

Although the road toward fully functional interoperable electronic health record systems will be bumpy, it is hard to imagine that we can achieve significant improvements in safety and quality without going down this road. The articles in this special issue will hopefully help to smooth the course toward more rational adoption of effective health IT systems.

Corresponding Author: Helen R. Burstin, MD, MPH; National Quality Forum, 601 Thirteenth St NW, Washington, DC 20016, USA (e-mail: hburstin@qualityforum.org).

\section{REFERENCES}

1. Merriam-Webster Dictionary. Available at: http://www.merriam-webster. com/dictionary/potential. Accessed January 30, 2008.

2. Kupersmith J, Francis J, Kerr E, et al. Advancing evidence-based care for diabetes: lessons from the Veterans Health Administration. Health Aff (Millwood). 2007;262w156-w168

3. Crosson JC, Isaacson $\mathbf{N}$, Lancaster $\mathbf{D}$, et al. Variation in electronic prescribing implementation among twelve ambulatory practices. J Gen Intern Med. 2008; 23: DOI 10.1007/s11606-007-0494-8.

4. Fischer MA, Vogeli C, Stedman M, Ferris T, Weissman J. Uptake of electronic prescribing in community-based practices. J Gen Intern Med. 2008; 23: DOI 10.1007/s11606-007-0383-1.

5. Garg AX, Adhikari NK, McDonald H, et al. Effects of computerized clinical decision support systems on practitioner performance and patient outcomes: a systematic review. JAMA. 2005;293:1223-1238.

6. Agency for Healthcare Research and Quality. 2006 national healthcare quality report. AHRQ Pub. no. 07-0013. Rockville, MD: U.S. Department of Health and Human Services, Agency for Healthcare Research and Quality; 2006.

7. Fung CH, Tsai JS, Lulegian A, et al. An Evaluation of the Veteran's Health Adminsitration's Clinical Reminder System: A National Survey of Generalists. J Gen Intern Med. 2008; 23: DOI 10.1007/s11606-0070417-8.

8. Hicks LS, Sequist TD, Ayanian JZ, et al. Impact of computerized decision support on blood pressure management and control: a randomized clinical trial. J Gen Intern Med. 2008; 23: DOI 10.1007/s11606-007-0403-1.

9. Weber V, Bloom F, Pierdon S, Wood C. Employing the electronic health record to improve diabetes care: a multi-faceted intervention in an integrated delivery system. J Gen Intern Med. 2008; 23: DOI 10.1007/ s11606-007-0439-2. 
10. Hess R, Santucci A, McTigue K, Fischer G, Kapoor W. Patient difficulty using tablet computers to screen in primary care. J Gen Intern Med. 2008; 23: DOI 10.1007/s11606-007-0500-1.

11. President's Information Technology Advisory Committee. Revolutionizing health care through information technology: President's Information Technology Advisory Committee report. Available at: http://www.nitrd. gov/pitac/reports/20040721_hit_report.pdf. Accessed February 4, 2008.

12. Kern LM, Barron Y, Blair AJ, et al. Electronic result viewing and quality of care in small group practices. J Gen Intern Med. 2008; 23: DOI 10.1007/s11606-007-0448-1.

13. Bates DW, Leape LL, Cullen DJ, et al. Effect of computerized physician order entry and a team intervention on prevention of serious medication errors. JAMA. 1998;280:1311-1316. (Oct).
14. Chaudhry B, Wang $\mathbf{J}$, Wu S, et al. Systematic review: impact of health information technology on quality, efficiency, and costs of medical care. Ann Intern Med. 2006; 144:742-752.

15. Wolfstadt J, Gurwitz JH, Field TS, et al. The effect of computerized physician order entry with clinical decision support on the rates of adverse drug events: a systematic review. J Gen Intern Med. 2008; 23 : DOI $10.1007 / \mathrm{s} 11606-008-0504-5$.

16. Dollarhide AW, Rutledge T, Weinger MB, Dresselhaus TR. Use of a handheld computer application for voluntary medication event reporting by inpatient nurses and physicians. J Gen Intern Med. 2008; 23: DOI 10.1007/s11606-007-0404-0.

17. Foster PN, Gadhia DA, DeMusis M, Sidhu R. Leveraging computerized sign-out to increase error reporting and addressing patient safety in graduate medical education. J Gen Intern Med. 2008; 23: DOI 10.1007/s11606-007-0503-y. 